\title{
Recovery \& Treatment of Sexual Addiction: An Interview with Dr. Patrick Carnes
}

\author{
Travis Smith* \\ Department of Educational Leadership and Counseling, USA
}

*Corresponding author: Travis Smith, Department of Educational Leadership and Counseling, USA.

\begin{abstract}
In this interview, Patrick Carnes, the world's leading expert on sexual addiction, shares his expertise on the topic of sexual addiction and the nuances and evolution of this prevalent issue. Dr. Carnes discusses the history of sexual addiction, along with gender differences and best practices when treating couples. Dr. Carnes also presents research supporting sex as an addiction, and how this influences treatment. In addition, Dr. Carnes also discusses the importance of disclosure in the process of restoring trust in relationships where sexual addiction has been present.
\end{abstract}

Keywords: Sexual addiction; Addiction recovery; Infidelity

\section{Biography}

Patrick J. Carnes, PhD, is the founder of the International Institute for Trauma and Addiction Professionals (IITAP) and Gentle Path Press. His extensive background in the field of addiction therapy led Dr. Carnes to develop multiple cutting-edge recovery programs aimed at treating addictive disorders. He serves as executive director of the Gentle Path Program, a residential treatment program for sexual addiction in Wickenburg, Arizona.

With more than 30 years in the sexual addiction treatment field, Dr. Carnes continues to spread his extensive knowledge as a speaker, presenter and interview subject. His assessment tools and related materials deliver an unprecedented approach to addiction recovery for practitioners of addiction treatment and sexual addicts.

\section{Historical Context and Development of Sexual Addiction}

Smith: Dr. Carnes, I want to thank you for your time. I understand you are very busy, but I think this piece that I am working on is important and having your expertise and experience will be so helpful to many trying to treat this particular issue. So, the first question that I have for you is, Dr. Carnes, when did you first become aware of the issue of sexual addiction?

Carnes: Well, I can give you the standard answer, which is in 1973 I was working with adolescents in the street and I went to my psychiatrist at the time and said, "I think sex can be an addiction", and my psychiatrist said, "I know that's true," and he helped me get a grant, and we wrote about it. The essence of that became eventually known as a book called Out of the Shadows [1].

A significant part of it was just by watching patients in a crisis intervention center, I was seeing sexual addiction in the street and at that clinic. I also started seeing patient's that that were very affluent, so I had a perspective that showed the existence of it on both sides.

I got involved with a group for sexual recovery in '77 and could see how 12-steps were really helping people with therapy and I was in a group where of the 10 members of that group, nine were therapists and the 10 th was a judge.

Smith: So, 1973, and Out of the Shadows came out in 1983. You worked on that for quite some time.

Carnes: Well, actually it was more about fear, I think. I would take the paper and do in-services, and it was like an underground document.

The first public event where I was actually talking about the book, I expected it to get all kinds of flack. As it turns out, people who were there were either people seeking help or clinicians that had clients they didn't know how to treat this sexually based 
problem. There was no contention, they just said, "What do we do?" But, the kicker in the story is, I got on the plane to go home and I am in the front seat of, coach section and I was sitting in the middle seat and the guy next to me said, "Well, what brings you to Washington?," and I wasn't comfortable talking about it. I said, "Well, I came here to do some work." He says, "Well, what do you do?" I said, "Well, I'm a psychologist." And, he says, "So, what did you speak on?" and I just finally unloaded it on him and let him have it. I said, "The workshop was on sex addiction, I just wrote a book about it," and he says, "Oh, I've got that book," and he reached into his briefcase and he pulled it out, and

he said, "You know, this is a very important book, but the publisher did it wrong." At that time, it was titled The Sexual Addiction.

And he said, "What they need to do is they need to retitle it, because write now if somebody buys it, it is like they are going to the cashier and facing the young lady there admitting they have a problem"

He went on to say that he thought the book needed to be a successful book, but needed to be totally redone. He asked if he had my permission to call this publisher and say, "You're missing the boat here," and I consented. Two days later the publisher called and said, "We spent the day on the phone with him and we have completely redone the book, and we would like to try some titles out on you, and the first one we would like to try is Out of the Shadows, Understanding Sexual Addiction." They redid the book and, millions of copies later, the rest is history.

Smith: So, even during the time, people struggled with compulsive sexual behavior, that is not the question; it's how do I present the idea to the masses in a way that is soft enough for them to hear it or consider it?

Carnes: Absolutely, and it still to this day is a problem, and there is a pioneering group in Canada that realized that the how to talk to the public about sex addiction is really key. They hired a Washington think tank called Frame Works and started cable and radio-based health series on addiction, and the impact it has on the brain. If you start with the brain and you talk about it as a brain disease and not food, sex, gambling or the like. So, in every hospital, every train station, and on cable TV people could watch this. After a period, they randomly checked to see if the public changed its attitudes about addiction and they did. The number one service that they thought was necessary was sex addiction.

\section{Defining Sexual Addiction}

Smith: How do you define sexual addiction?

Carnes: Now to underline why that is important is that in North America addiction is our number one public health problem. If you look at substance abuse, alcoholism, abuse of prescription drugs, which is huge because over two-thirds of American adults have used a pain killer like hydrocodone for nonmedical purposes, and then you add in a third of our population is obese, which is about compulsive overeating and an addiction problem; and then you add in the sex addiction and nicotine, and I mean you mix it all together, that is why we have things like the costs that we do.

If you start from the point of view of it's a brain disease and, once people understand that food and gambling become addictive and that it doesn't have to be a chemical, the sex part becomes easy. That is important from a public policy point of view, because it helps us to understand how people can make sense of something more than just character issues.

We use many different definitions of sex addiction. It's a little bit like physics and defining light. In one way it's a set of particles, another way it's a set of waves. So, you ask which is it and the physicist will tell you it's both. ASAM (American Society of Addiction Medicine) has a definition that they have come to, is that the neurobiology of addiction is becoming very, very clear. And, so, they define it as a brain disease in which the brain is fundamentally altered and rewires itself so that the individual then makes consistently recursive poor choices around food, sex, money, alcohol, drugs. ASAM includes process addictions in their general definition of addiction, which is important on many levels.

Smith: So, when you talk about addiction and brain disease, you're talking about neuroplasticity?

Carnes: Neuroplasticity is key to that. One theoretically framework is that there is brain damage, which is visible and measured through imaging. We use the same standard 10 criteria that have been used for disordered gambling and substance abuse; they also work for sex addiction. Criteria like loss of control, consequences because of acting out behavior and yet you do it anyway, feelings of regret or guilt and repeated attempts to quit are hallmarks of addiction.

I have just finished a paper in which we had 4400 people participating that were sex addicts, inpatient/outpatient, that fit the 10 criteria. Now, in the DSM it is a theoretical. It is like depression where you can assess for depression, but you can have lots of different reasons that you think that depression is there. Sex addiction, of course, is that same way, except in the addiction's case the neurobiology of this is starting to take over things. But it is also a maladaptive response to trauma because we know people who were abused as children, the more abused they were, the more addictions they tend to have as an adult. In the mid 90's Bruce Perry did a series, The ACEs survey, which found the same thing, that early childhood, early attachment, was a predictor [2]. It's a mental adaptor response to stress. It is also a family issue and multigenerational. It is also a failure to bond, and an attachment issue. Only $8 \%$ of sex addicts test out as a secure attachment. So, these issues, family dynamics and family history of addiction, child abuse, sexual abuse and attachment styles are all essential aspects of treatment.

Smith: Can you speak to the impact the Internet has had on the prevalence of sexual addiction in the general population? 
Carnes: There are these different things that are all true about sex addicts that we know. A factor, that is a game changer in this whole thing, is that the Internet has made such an extraordinary change in everything, but in our sexual behavior, it truly is changing our sexuality as we speak.

One study shows that about two-thirds of our junior high students doing sexual things while they are doing their homework. And, their assessment is that $34 \%$ of them are doing it at such a level that the brain changes that are occurring, they are going to have a long-term, lifetime problem with chronicity around this issue [3]. That is a very important paper because most parents do not realize that their kids are being sexual to the degree that they are. To further problem of that, there is a growing understanding that between the ages of 12 and 16 the malleability of the brain is incredible. If you smoke at that age it increases the difficulty of giving up smoking as an adult. Getting drunk repeatedly at 12, 13, 14 , puts you at very high risk.

The Internet allows kids to become saturated early, and so when you ask me how to define sex addiction, this aspect of saturation is very important. The answer that I would give you now is different from the definition I would have given you 10 years ago. We understand now, from a sexual point of view that we didn't understand before, is that the Internet allows visual and auditory stimulation in intense and rapid sequences and the variety of sexually stimulating material is limitless. In the neuroplasticity of things there is another phenomenon we call imprinting. When I went to school, and I bet you when a lot of your readers went to school, I was told that your sexuality is pretty well defined between the ages of 5 and 11. Arousal that is experienced on the Internet teaches the brain that in order for arousal to really work, to get that ideal level of stimulation, novelty has to be part of it. It needs to be something new or different. And, that means two things. First, the arousal template is changed and is on a constant quest for something you haven't done before, something new and better.

The second part is there are many people who are now sex addicts that would never have become had it not been for the Internet. Because of that, sexual addiction is, in some ways, an artifact of the Internet. Part of it is almost always Internet related.

Smith: I am 34 years old and I didn't own my first computer until I was 21, and many people struggling with compulsive sexual behavior are in this age bracket weren't exposed to the internet the same way that people are today.

Carnes: We have a tsunami coming. It's huge, and I am seeing it as are a lot of therapists. I get people in their 30s, like you. But, in 1995, they were on the internet and started looking at it, and so, even though they are young people, they have a habit they have had since they were 15 . The real problem is when you got, and about $40 \%$ of men are looking at it by the 5 th or 6 th grade, and this is not looking like at Dad's Playboy. What you are looking at is something so stimulating that the result is people get more stimulation looking at pornography than real sexual experiences with people. Many people who develop the addiction have never dated. Their sexuality was totally in this other universe. They never held a woman's hand, they never kissed a woman, none of it. They have been sitting in a chair; so, they don't know how to relate to people.

\section{Sexual Addiction as an Intimacy Disorder}

Smith: So, there is the brain component, but there is also the intimacy and attachment component.

Carnes: Absolutely.

Smith: And do you treat those two things in different ways?

Carnes: We use Fraley's attachment matrix, and it is very clear to us that being in isolated, self-stimulated lust only produces devastating results [4]. The two top reasons that kids drop out as freshman in college is because of internet porn and because of prescription drugs. Prescription drugs are a huge problem started as a teenager, and because they are all over the house because the parents have them, and people don't realize what a huge problem it is, and then the other one is internet porn, and if you're viewing porn 20 to 25 hours a week, you can't keep up a college career, and so they flunk out. That is a very common. If you went to student counseling bureaus across the country, you would hear students talking about this issue as a common issue.

Smith: What are some of the hallmarks, or tells, of a sexual addict?

Carnes: Well, first of all, the things that I think that you'll look for, like when $\mathrm{Al}$ Cooper did his first study of sex on the internet and he used the Triple-A Engine, and he talked about the fact that it was affordable, anonymous, and accessible [5]. In fact, part of the problem, but one of the criteria that he used, is, you know, people who are using pornography, and he determined from their data, their first study was 9000 and the second one was 40,000, eight hours a week. If you were doing over eight hours a week of sex on the web, you know you probably had a problem. I think when you quantify that, it is a little bit like...I will have reporters ask me, well how many affairs does it take to make a sex addict, which is a little bit like asking how many drinks make an alcoholic, you can't measure or quantify it that way.

Carnes: We developed an instrument called PATHOS Carnes PJ, et al. [6], which captures the essence of the phenomenon, and it was patterned after a thing called the CAGE.

We distilled six items that did the same thing, and worked as well as the CAGE for both men and women, and it is called PATHOS, and the things that stand out are, first the, literally, the preoccupation and, so that you are thinking about it all the time. It has been a real help to physicians and is in a second round for the Journal of Pastoral Counseling.

It is a little-known fact, but we found that two-thirds of sex addicts have been in an emergency room because of something they have done sexually. That was a very startling statistic to me. Ranging from being injured because they were doing high risk 
sexual practices, heart attacks at a massage parlor, car crashes because they were masturbating while driving. It's a wide range of stuff that actually happens.

PATHOS is organized around the premise that at least 3 of these criteria are met. Preoccupied with sexual thoughts. Then ashamed is the A, of the sexual behavior; T for treatment, have you sought out treatment for the issue previously. And, it actually has become codified in that in PATHOS the T is you sought therapy for sexual behavior you did not like. $\mathrm{H}$ is for hurt others, and $\mathrm{O}$ is for out of control and, in other words feeling like they can't stop their behavior, and S for sad. One of the characteristics of sex addicts is to feel depressed immediately afterwards, or even as they are doing it, to be in such a struggle of doing stuff that they don't want to do.

We have a thing called a Sex Addiction Screening Test Carnes PJ, et al. [7] which helps identify possibly trauma, because classic childhood trauma is highly correlated with sexual addiction.

One of the common signs of an abuse victim, especially in that group of people that Ken Adams writes about in his book Silently Seduced Adams K [8] and When He's Married to Mom Adams K [9] where the boy growing up has been a special confidant of Mom, the special kid in the family and an absentee father, that model of kind of almost emotional incest, sharing things that you should never share with a son. I mean sharing your marital business with your kid kind of thing. What that does is it makes it hard...or if you were sexually abused outright, what that does is it makes it very hard to love someone and also be sexual with them. That is a very common experience, which I think largely sexology has missed the reality of that, whereas the family and marriage people have been more aware of that dynamic; and, so, anyway, the upshot of it is you have, in that discrepancy where the presenting issue was something not about, maybe not even about sex, it could just be about the emptiness of their marriage, we don't know why we're together. You'll find a person, one or the other partner, is acting out and, when you separate them, and then you have the problem of, okay, so, I know all this stuff about one partner and it really needs an intervention, and the other partner doesn't know what is going on, you get into all kinds of issues fairly early. But it is a very common model for how family therapists get involved with it.

\section{Treatment Modalities and Best Practices}

Smith: What are some of the positive changes related to the treatment of sexual addiction that you have seen over the course of your career?

Carnes: I followed 1000 families for seven years, and their partners, and we published those results in the early '90s in a book called, Don't Call It Love Carnes PJ [7] and what was very useful for me in that book was that there was a pattern of success that we were able to see that really made a difference. So, I will tell you what that pattern looks like, and then I will tell you what I think we have learned since then. The pattern was is that it seemed that the first thing is they had a therapist that they rode with for about three to five years. There is always somebody they really trust. If you go back to what you know about neuroscience, in order to get brain, change one of the first things you have to have is safety; and, so, it must be someone that they really trust. It's also somebody who holds them very accountable. It is very important to have that accountability. Now, that therapist may send them to a treatment center, may send them to an intensive workshop, or may send them to do some work on trauma with somebody. It is like being a primary contractor, you send them out to get various thing and you oversee that process over time.

The second thing that is really important is they must be in a group. The ability to attach in healthy ways is huge. Group, as well as psychotherapy, is really important. The average is about 175 hours of group and those people did the best.

The third thing is that they went to 12-step meetings and there are a lot of reasons that the 12-step groups really work well, and, from a neuroscience point of view, if we were to take the primary findings about, you know, how do you change a brain? The 12-steps actually help with lots of those things. There is models that you can plug in; like, if you take Dan Siegel's nine domains of integration, it is basically a prescription for the 12 steps [10].

We're starting to understand, why does it work? Well, for one thing, if safety is the first thing you have to have, like when Amnesty International was trying to get torture victims to go through therapy, they wouldn't go, until they were put in a room full of other torture victims. Then they felt safe enough to really talk, because they were talking to people who had been there. We found fairly early in the outcomes of our research that the percentage of people who went to meetings and found a good group, and attended counseling was only $23 \%$, but of those people in that category, there was virtually no relapse.

And the fourth thing that we found is they have to actually do it. In other words, it is doing the steps. It's not just going to meetings. It's doing the work. The therapist actually has to be monitoring and helping with that, because if you take step four and five, which basically are affect education, the therapist needs to be intimately involved in that fourth and fifth step because it is literally how the patient starts to get their conscience back. Their moral compass and their ability to tolerate negative affect is one of the major thresholds in recovery that has to happen. The therapist is very involved with this step work.

And then the fifth thing that we found that was very important is simply involving the family in the process ups the ante in terms of recovery.

What increases that dynamic is number six is when the family members realize that they are part of the problem. The term that has been used, codependency; but, those of us who understand family systems knows that everybody has a stake in this thing, and that they have done things which have contributed to the problem. And, so, the harder that the spouse pushes on the addict, the more the addict acts out, for example. 
Number seven, in the Handbook of Family Therapy they discuss times when a counselor provides treatment for someone individually but the problem is really a family problem, and you do it individually, you often make it worse.

That has happened in the 12-step community for years, because they go to separate programs: AA, Al-Anon, OA, O-Anon, SA, S-Anon. In other words, you go to separate groups. The group never gets the chance to hear the partner's perspective on things. It wasn't until those groups, and its different formats, Al-Anon, S-Anon Family Group, but perhaps the best one maybe is Recovery Couples Anonymous. People who did that, in our first major follow-up, one of the findings is they did the very best of everybody. Being in not only their individual 12-step group, but doing the couples group, and then being in family therapy, as well as individual therapy and group therapy in the practice, it's really huge in this sense.

The eighth thing that was really important for people was spirituality, and we therapists like to think it's all our skills and everything, but when we've asked of all the things that helped you to get well, they talk about a spiritual life. Now, like the 12-step programs, it's not whether your Jewish or Christian, or whatever, or Buddhist, it makes no difference, but these people really need to get in touch with their own spirituality.

Smith: What are the hallmarks of recovery? I mean, what does the work of counseling look like for a sex addict?

Carnes: What it has to do with, in order to go through the struggle that is now necessary, to totally reengineer your life, there is a lot of pain involved. You're confronting your deepest demons. There's an agony to it, and it's a little bit like Viktor Frankl about the concentration camps, about the people who were able to transform suffering into meaning [11].

The core of recovery is resilience, and resilience comes from taking that which is bad and making it into something powerful and meaningful in your life. Resilience skills like gratitude, you doing gratitude lists regularly, learning how to reframe negative perceptions into positive, the serenity prayer, letting go. In other words, a lot of this has to do with that ability to take the ugliness of your life and to learn from it and to start having an inner observer in your brain that psychologically detaches itself and then monitors the traffic of the brain. That is really what a spiritual life is about. It means being able to, like Henri Nouwen talks about the first movement of spirituality is also the first movement of psychotherapy, which is to be able to be with yourself, and uses the phrase "converting loneliness into solitude" [12]. Most sex addicts have a hard time being by themselves.

They will find something to stimulate themselves. They can't be in a hotel room. The whole notion of the deep stillness that you need to go through to hear what is really going on with yourself is foreign. They don't have a connection with themselves. He says that if they don't connect with themselves, they can't connect with others, if they can't connect with others, then they cannot connect with a higher power [12].
There's a whole series of trust issues. If you have been trying to stop something, and this is for all addictions, and you always fail at it, you don't trust yourself very well. As you start to grow and you have this structure to be able to change yourself, and start to build trust for yourself, all your relationships shift and they deepen and become more meaningful.

The final thing that really made a difference is your personal health care. I didn't understand this at the beginning, the way that I understand it now. But it seemed that the person who exercises, eats well, what have you, did better. Now we know that all those things that you do to help your heart, for example, also help your brain. One of the things that sex addicts have to learn, they have to learn about their body, how their arousal works, how the neuropathways of the brain work; but, they also need to become good consumers of health information about the brain. They need to learn about plasticity. They need to learn why what we call mechanisms of attention that they need to cultivate, focus, and be able to really retrain their brain, so that it becomes easier to the point that you don't think about these problems anymore. That happens about the turn of the first year of sobriety.

Smith: Are you talking about mindfulness?

Carnes: Well, this is extremely a lot of it, but it's more than that. It is really having a tool kit that really helps you stimulate your brain into activity that helps you focus on changing your life and to getting closer to being where you want to be.

Smith: As clinicians work to provide effective treatment, what do you say is misunderstood about the needs of the population?

Carnes: If you step back.....and, we use a motto in our materials, we were very influenced by Mihaly

\section{Csikszentmihalyi and the book Flow [13].}

That book really was about addiction, and a lot of people focus on the flow part, and the addiction people overlook the flow part. Basically, he said getting sober is not the problem, the real problem is staying sober. In any addiction, if you're going to change you need to rearrange. Your life is very habitual. You have to re-change how that habit works. His whole point was, is that he looked at the people of great achievement, and he found people of great achievement used their brains the same way that addicts did. And, that is why so many people of great talent, and are public figures, addiction is so prevalent in that group. He points out that the brain always craves challenge, and when you are in the grove, or in flow, or what we call the recovery zone, you are more likely to experience success.

When you are really living your life where you want to be, then you have your best success. And, what I think happens, frankly, and there will be people who will be upset by my saying it but, what I think happens is so many in the addiction treatment community focus on staying in the here-and-now and living a day at a time and, the fact is, if you just do that you're going to have relapse.

The fact is we use a paradox that we got from an Admiral who was in Vietnam and in a prisoner of war camps. What he said is the 
people who got out of the camps, that really were good at surviving, realized the first thing is you really had to accept the reality of how bad things are. Then you have to have a vision that you're going to return home and envision what that's going to be like and what that means to you.

Without that vision and purpose, you do not have the persistence to get through the very difficult times. I believe this is hard work, and there are three things need to be accounted for. First of all, I think therapists give up too soon.

As soon as the crisis is over and the behavior seems to be attenuated, and the wife has calmed down or the husband has calmed down, and things have sort of returned to normal, the clients become less interesting. I think therapists are drawn to the drama of their clients and they get the priority. Addiction therapy is a three- to five-year process. And, there is a deep inner work that is not exciting, and if kind of tough slogging week after week that therapists get bored with. And, I think that they stop when the patient is well enough to get by.

What I see, and we noticed in the field, that one of the real signs of progress, ironically, is when both partners in a relationship have made so much progress that they realize that they are really living with a different person now.

They need to remarry or recommit. That is when family work really comes into its own. Because then you can start looking at non-negotiables, the kinds of things that family therapy excels at, but you've got to get them to the point where they can really do that level of therapy, so that they move into the thriving, being at their best. You have actually improved brain functioning, and they are living a much happier life.

Smith: What are some of the other mistakes that you think counselors commonly make when treating sexual addiction?

Carnes: Well, I think one of the things that many therapists who come into the field don't realize is that they need to be examples of the recovery process and healthy living. The number one predictor of success was that the patient believed that the therapist would do what the therapist was asking them to do; in other words, modeling.

We all are human, and I think you've had, and I know I have had, the experience of giving someone a series of recommendations or advice, and realize if I did that for myself, I would be a lot better off? Have you ever had that?

Smith: Yes, frequently.

Carnes: But the reality is, the patient has to believe that the therapist has done this level of work themselves. If not an addiction, they have done their own therapy, they do their own therapy, they are in supervision. They're not on this pedestal, like God, but they are people who are real people but just further down the trail than they are. That is very important. What it does is it gives credibility to the therapist to hold the patient accountable. Family therapists are notorious for not holding the patient accountable, because they don't want the patient to go away. Often times, the best thing you can do for a patient, if they are not doing and following their contracts, is to say, "You know what? What we're doing isn't working. I will refer you to someone else." Kicking them out of therapy, and only working with them if they are improving is a key with addicts. It's key. This is not client centered therapy, because their lives are at stake and you can't fool around with it. The very best therapists in our CSAT system, the certified sex addiction therapists, are the ones that sometimes are the very toughest. The whole point of it is that holding them accountable is a real critical thing.

I think the biggest challenge is the long-term management of addiction, it is sort of a specialty itself. We're talking about trauma treatment. We're talking about family treatment. We are talking about group. We're talking about getting into meetings. There is a lot of management and complexity to the amount of care that an addict needs, which is not fitting into the 50-minute hour. The addict coming out of treatment where they have been in a highly structured living environment, and the brain was always occupied, and then you call the referring therapist and the office administrator says, "Well, sorry but she is going to be in Paris for the next six weeks." Coming straight out of treatment and not being able to see your therapist is a terrible experience.

Smith: It may resemble abandonment.

Carnes: Exactly. Good therapists have groups that specialize in addiction. If you stop to think about it, the 50-minute hour takes about 10 to 15 minutes to catch up, then the real work starts, and then you do that work and then you've got to button them up so they can walk back to work and be contained. So, in that 50-minute session, you have 20 minutes of work time. It would almost be better, and many of our people do this with addicts, is to take them for three hours, where they get down and your focus on these issues. It's a different way of thinking about practice, and that intensive model is what a lot of people who do long-term addiction treatment are moving to. There needs to be more structure and more time and more group.

\section{Relationship Recovery \& Restoring Trust}

Smith: I want to get your perspective on attending to relationship and family issues in treatment. You've referenced the importance of the inclusion of the couple or the family in the treatment process. I'm wondering if you could talk about the differences in individual and relationship recovery.

Carnes: I reference the three-legged stool...my recovery, your recovery, our recovery. I will tell you the very worst thing that can happen is when the spouse is seeing one therapist in one office, and the addict is seeing another therapist in another office, and those two therapists do not agree on the course of treatment. It is so destructive, especially if the partner's wife does not understand addiction or the implications of addiction or the how the brain has been impacted. They have no concept of that. They see this essentially as a matter of betrayal. If they are not on the same page with the treating therapist, that's a disaster. And, so, it is best to keep them in the same practice, maybe seeing different people, 
but all the people who are seeing them need to be on the same page and sharing the same goals. What happens is you are talking about a three to five year period, and even at the very beginning we found that about two-thirds of the spouses were actually, in their knowledge of sex addiction, about three to six months ahead of the addict in terms of awareness of what was necessary. So, the couple is not on the same page. Or, we found the opposite to be true, where the addict got into trouble, knew there was trouble, accepted it, but the spouse said you go to therapy and get it fixed and doesn't want to participate. Usually that's because they have deep trauma around these issues and their past, and they know to walk into a therapist's office is going to result in an unraveling, and so there is resistance.

When the trouble breaks, it's a shock to the partner. There is a school of thought, which is becoming widely accepted, that if somebody chooses alcohol over you it's one thing, but when somebody is actually sleeping with somebody else, or numbers of people, the betrayal is very real, and there's a PTSD equivalent in that.

Holistic recovery and relationship recovery require getting through the betrayal part of it. Daniel Amen, who has done brain scans with sex addicts, talks about the utility of showing the brain changes to the spouse. So, it helps the spouse to relax and even have compassion and empathy because there is a new conceptualization of the presenting problem. It reduces the "I've been wronged by my partner" mentality.

It's really complicated with things like food and sex, because in all the process addictions you can give up alcohol, you can give up cocaine, but for a food addict every meal is a choice, and for a sex addict every day is a choice. But you can get to this point where you can measure the fact that the cravings aren't there when the set point of the brain calms down and they are able to make good decisions. It's very visible, there's not the dopamine spikes that you would typically expect for people who are relapsing.

I think Amen is right when he says that mental health is the only branch of medicine that doesn't systematically look at the organ it's treating. I believe he's right about that. We have to look at the brain and help clients effectively heal and develop brain functioning, but also help partners understand that addiction, in every sense of the word, is a disease of the brain.

Disclosure and Recovery

Smith: The neuroscience research coming out is truly compelling and I appreciate you bringing it up in our conversation. I am going to shift gears here to a different topic. Something that comes up frequently in the treatment of sexual addiction is the issue of partial truths. Maybe the addict has shared snippets of their addiction but hasn't made full disclosure to a spouse. And, I've spoken with many clinicians that have struggled with situations where the relationship seems to be doing well, but now the client is saying there's more to the story. The clinician doesn't want to disrupt the relationship and at times feel stuck. What are your thoughts on assisting with full disclosures?
Carnes: That's not a question, that's a workshop. The very worst is when the clients try to handle this themselves, without a therapist. Because there is no containment, there's none of the teaching or guidance that is necessary to make sense out of the behavior that's present, and terrible damage can come out of that; so, unsupervised: not good.

Secondly, it becomes like a Chinese water torture to the spouse to have it dripped out to them. They will ask the spouse, "Well, is this all?" The spouse will say, "Yes." And then there is more. So, the building of trust does not work. It's more than the things that have been uncovered by the spouse, that real trust can get built in what we call emotional restitution in giving, what is called a full disclosure.

The real problem, first of all, is to get full disclosure with a therapist. And, from a family systems point of view, patients historically have come usually to use the circumplex model of family therapy Olson D [14] from the rigid disengaged side of things, which is a family that very easily compartmentalizes and has a huge distrust of any kind of accountability or authority. So, it's a family of origin problem. That compartmentalization problem is very, very real. So, what the therapist has to work for is to really make that one of the conditions of being in therapy, that there are no secrets with us. We will help you eventually get clear with your spouse, and that the disclosure can be you can't live in an intimate relationship. Sooner or later there's going to have to be a laying out the whole picture, not all the details, but there has to be a laying out of the whole picture. Because, if it doesn't happen, what occurs is that no matter how impossible it is that the addict thinks that the wife or husband won't find out, it happens, and they do find out. Then you're in another crisis cycle. So, you have to work for disclosure.

Here's the other side of this disclosure and is a real problem, is what about kids? And, the truth is sometimes the kids are right in the center of it. When you discover your father's pornography and you're the whistle blower, you're right in the middle of it. And, the other problem is, is that you have families in which you have more than one person who is having a problem, multigenerational.

This is a problem that I don't think anybody has answers for yet. There are kids, fifth, sixth, seventh graders, that parents who are wondering what to do. The kid has seen all sorts of stuff that his or her young mind can't begin to comprehend but there is real strong arousal. He's seen all of these things, and he's been locked in the bathroom, and we now know what he is looking at. Well, you know, the best you can do is to talk with your children; but that kid now knows how to get access.

We do not have a structure for that problem yet; and, it's because most of us working in the field have got our hands full with the adults with the problem.

\section{The Changing Tide of Sexual Addiction}

Smith: How has sexual addiction evolved over the past 10-15 years? 
Carnes: I can show you data within the past 20 years where 1 out of 4 women would be involved in an affair or something like that, whereas now it's a 50/50 probability. We have a military that has got women and men fighting together in intense situations, and then expect to go home to a spouse, and when they feel more bonded with the person that they have been carrying a machine gun with. All of these things are changing. The fact of the matter is our species for years had it set up that men had power and women spent $90 \%$ of their time delivering eight children with the hopes that two would live.

Well, now the average birth rate across the whole planet, in developing world, is 1.6. So, you have all these women coming online who are bright and wanting to have a different life, and what have you, and to conservative religious denominations, of all varieties, this is threatening. We seem to be emphasizing less partnership and more independence. This is very scary too but, what we know is that in partnership cultures, there is less violence. But, we are at such a precipice about this that I think that we need to stop and realize that, you know, when Eisler wrote her book The Chalice and the Blade Eisler R [15] and she was talking about the benefits of having a partnership culture, how threatening that way of living would be to people who are basically in the third world living with a different model of what family and sex is.

And, with the United States, we are the democracy setting the pattern of the world, and, you know what, we produced $400,000,000$ pages of pornography last year. The closest country to us was Germany with 10,000,000.

Smith: You seem to be alluding to how women are being impacted. I am wondering if you could speak to the gender differences with sex addiction. In what ways do men and women differ in sex addiction?

Carnes: It is pretty clear that men tend to things that are more objectifying, and women to things that are more about power and control. And, so men tend towards pornography and nonrelational kinds of sex, and women tend to things that had more power components to them, like conquests. The fact of that is that the internet has changed that. I now have got women with huge internet pornography collections and acting out in ways that would typically be more 'male'.

But, what is curious to us, and we're working on this, but it seems that women are much more varied in the ways they will experiment sexually than men are, and, as a result, there's a view of a women sex addict, she's probably done more than the average male sex addict would, in terms of varieties of experiments.

Smith: That surprises me, and I suppose it would come as a surprise to the readers as well.

Carnes: Sure. Well, there's another piece to it that's kind of interesting, which is they are less likely to get caught too. And, the reason is that women have an extra band of memory to remember details that men don't. It's why men don't like to fight with women, because a woman will looks at you and, "Oh yeah, I remember when you had the awful checkered shirt on, it was 7:32 Friday night, September 17th, I remember we were doing this" and the guy can't even remember what he was doing in September. I mean, I can tell that story in an audience and everybody will laugh because they know that's true. But, when it comes to acting on it, the women pull off more than men do because they remember who they said what to.

Smith: I want to ask one more question to you before we wrap this up. What's been the most rewarding or fulfilling part of doing your work with sexual addiction?

Carnes: Well, I mean, every day I learn things I didn't know before. Any time you have a job that really matters, and people get better, and you come away with a feeling like you've continued to learn, that's a good job. The things that we are doing now, some of it is pretty significant, and to be part of a research team that is finding things with very strong science behind it is very rewarding to have questions answered. My wife died some years back, and I found that when I got back and started to return to work, and I started to be able to see that all the data that we gathered while she was sick was materializing into something that could be really useful to people it was exciting to me and helped me get through a difficult period.

Smith: Well, Dr. Carnes, thank you for giving so generously of your time and for your work on this important issue.

Carnes: You are very welcome. Thanks for having me.

\section{Acknowledgements}

None.

\section{Conflict of Interest}

No conflict of interest.

\section{References}

1. Carnes P (1983) Out of the shadows: Understanding sexual addiction $1^{\text {st }}$ edn. Hazelden Foundation, US.

2. Dube SR, Dong M, Chapman DP, Giles WH, Anda RF, et al. (2003) Childhood abuse, neglect, and household dysfunction and the risk of illicit drug use: The adverse childhood experiences study. Pediatrics 111(3): 564-572.

3. Mitchell KJ, Finkelhor D, Wolak J (2001) Risk factors for and impact of online sexual solicitation of youth. JAMA 285(23): 3011-3015.

4. Fraley RC, Shaver PR (2000) Adult romantic attachment: Theoretical developments, emerging controversies, and unanswered questions. Review of General Psychology 4(2): 132-154.

5. Cooper A, Scherer CR (1999) Sexuality on the Internet: From sexual exploration to pathological expression. Professional Psychology: Research \& Practice 30(2): 154-165.

6. Carnes PJ, Green BA, Merlo LJ, Polles A, Carnes S, et al. (2012) PATHOS: A brief screening application for assessing sexual addiction. J Addict Med 6(1): 29-34.

7. Carnes P (1991) Don't call it love: Recovery from sexual addiction. Bantam Books, New York.

8. Adams K (2011) Silently seduced: When parents make children their partners. Health Communications, US.

9. Adams K (2007) When he's married to mom: How to help motherenmenshed men open their hearts to true love and commitment. Simon \& Schuster, New York. 
10. Siegel DJ (2001) The developing mind: How relationships and the brain interact to shape who we are. The Guilford Press, New York.

11. Frankl V (1946) Man's search for meaning $2^{\text {nd }} e d n$. Ebury Press, UK.

12. Nouwen H (1999) The inner voice of love. Image Publishing, Australia.
13. Csikszentmihalyi M (2008) Flow. HarperCollins Publishers, New York.

14. Olson D (2000) Circumplex model of marital and family systems. The Association for Family Therapy \& Systemic Practice 22(2): 144-167.

15. Eisler R (1988) The chalice and the blade: Our history, our future. Haper One, USA. 